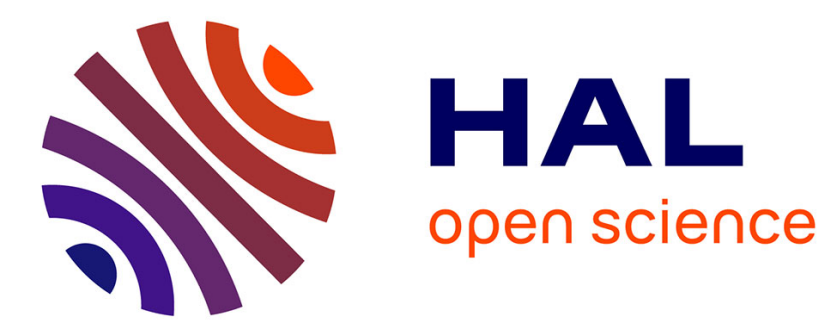

\title{
Devriesea agamarum causes dermatitis in bearded dragons (Pogona vitticeps)
}

Tom Hellebuyck, An Martel, Koen Chiers, Freddy Haesebrouck, Frank

Pasmans

\section{- To cite this version:}

Tom Hellebuyck, An Martel, Koen Chiers, Freddy Haesebrouck, Frank Pasmans. Devriesea agamarum causes dermatitis in bearded dragons (Pogona vitticeps). Veterinary Microbiology, 2009, 134 (3-4), pp.267. 10.1016/j.vetmic.2008.08.021 . hal-00532468

\section{HAL Id: hal-00532468 \\ https://hal.science/hal-00532468}

Submitted on 4 Nov 2010

HAL is a multi-disciplinary open access archive for the deposit and dissemination of scientific research documents, whether they are published or not. The documents may come from teaching and research institutions in France or abroad, or from public or private research centers.
L'archive ouverte pluridisciplinaire HAL, est destinée au dépôt et à la diffusion de documents scientifiques de niveau recherche, publiés ou non, émanant des établissements d'enseignement et de recherche français ou étrangers, des laboratoires publics ou privés. 


\section{Accepted Manuscript}

Title: Devriesea agamarum causes dermatitis in bearded dragons (Pogona vitticeps)

Authors: Tom Hellebuyck, An Martel, Koen Chiers, Freddy Haesebrouck, Frank Pasmans

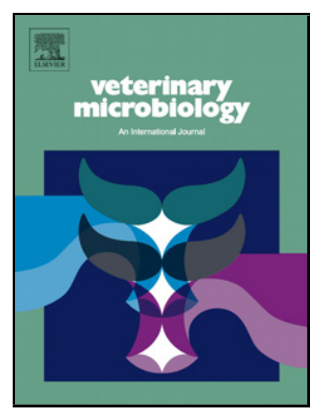

PII:

S0378-1135(08)00331-3

DOI: doi:10.1016/j.vetmic.2008.08.021

Reference: VETMIC 4117

To appear in: $\quad$ VETMIC

Received date: 13-3-2008

Revised date: 29-7-2008

Accepted date: $\quad$ 14-8-2008

Please cite this article as: Hellebuyck, T., Martel, A., Chiers, K., Haesebrouck, F., Pasmans, F., Devriesea agamarum causes dermatitis in bearded dragons (Pogona vitticeps), Veterinary Microbiology (2007), doi:10.1016/j.vetmic.2008.08.021

This is a PDF file of an unedited manuscript that has been accepted for publication. As a service to our customers we are providing this early version of the manuscript. The manuscript will undergo copyediting, typesetting, and review of the resulting proof before it is published in its final form. Please note that during the production process errors may be discovered which could affect the content, and all legal disclaimers that apply to the journal pertain. 
1

2

3

4

5

6

7

8

9

10

11

12

13

14

15

16

17

18

19

20

21

22

23

1

3

4

\section{Devriesea agamarum causes dermatitis in bearded dragons}

(Pogona vitticeps)

Tom HELLEBUYCK*, An MARTEL, Koen CHIERS, Freddy HAESEBROUCK, Frank PASMANS

Department of Pathology, Bacteriology and Poultry diseases,

Faculty of Veterinary Medicine, Ghent University.

Salisburylaan 133, B-9820 Merelbeke, Belgium

,

2

8 *Corresponding author: Tom.Hellebuyck@UGent.be

Tel.: +32926474 42

Fax: +3292647490

Department of Pathology, Bacteriology and Poultry diseases, Faculty of Veterinary Medicine, Ghent University. Salisburylaan 133, B-9820 Merelbeke, Belgium 
Abstract - Devriesea agamarum is frequently isolated from dermatitis in lizards, notably from cheilitis in spiny tailed lizards (genus Uromastyx). It was the aim of the present study to assess the role of this bacterium as a causative agent of dermatitis by fulfilling Koch's postulates. First, its association with diseased lizards was demonstrated. The bacterium was isolated from several, mainly desert dwelling squamate species showing symptoms of dermatitis and / or septicaemia. The affected lizards mainly belonged to the family of the skin is breached. 


\section{INTRODUCTION}

49 Dermatitis is one of the most frequently occurring diseases in captive reptiles 50 and is often associated with bacteria (Chineme and Addo, 1980; Pasmans et al., 2007 ), fungi (Frank, 1976; Jacobson et al., 2000) and viruses (Raynaud and Adrian, 1976; Herbst et al., 1999).

Although a variety of bacteria have been associated with dermal disease in captive lizards, their role as primary etiological agents in the onset of dermatitis is questionable (Jacobson, 1992). Predisposing factors such as environmental mismanagement (humidity, temperature, social stress) or other diseases (gastrointestinal, respiratory, ectoparasites) are thought to be of major importance for the development of dermatitis. An unknown member of the phylum Actinobacterium has been isolated from a number of dermatitis cases, mainly in agamid lizards. It has been particularly associated with chronic hyperkeratosis presented as lip and skin fold dermatitis in spiny tailed lizards (Uromastyx sp.) (Koplos et al., 2000; Pasmans et al., 2004).

The aim of the present study was to determine if D. agamarum is a cause of dermatitis in captive lizards. Additionally, we determined whether $D$. agamarum is a part of the cloaca, skin and/or mouth microbiota of clinically healthy lizards, freshly hatched lizards and squamate eggshells.

67

68 
2.1. Association of Devriesea agamarum with clinical cases of dermatitis in lizards

Over a 3 year period, 28 lizards with dermatitis, occasionally associated with septicaemia, were sampled for the presence of D. agamarum. Either swabs (Copan innovation, Italy) from dermal lesions or samples from internal organs and bone marrow were cultured during 24 to 48 hours on colistin nalidixic acid (CNA, Oxoid $\mathrm{GmbH}$, Wesel, Germany) agar at $37^{\circ} \mathrm{C}$ and $5 \% \mathrm{CO}_{2}$. All isolates that formed smooth, mucoid, whitish small colonies and produced small alpha haemolysis as reported by Martel et al. (in press) for D. agamarum, were analysed using $\mathrm{API}^{\circledR}$ Coryne, $\mathrm{API}^{\circledR} 20$ STREP, $\mathrm{API}^{\circledR} 50 \mathrm{CH}$ (bioMérieux, Marcy l'etoile, France) and 16S rRNA gene sequencing, as previously described (Martel et al., in press).

85

86

2.2. Occurrence of Devriesea agamarum in clinically healthy lizards and squamate eggshells

89 Thirty-eight Pogona vitticeps and 21 Uromastyx (12 U. acanthinura, 7 U. geyri, $1 U$. ocellata and $1 U$. dispar) without dermal lesions were examined for the 
applicator at 3 places: 1) the paramedian midbody area of dorsolateral skin 2) the edge of the upper lip and 3) the pericloacal region. Two of the sampled $P$. vitticeps were housed together with an $U$. acanthinura showing marked cheilitis and dermatitis. All remaining $P$. vitticeps were reared in segregation from other lizard species. Additionally, 28 neonatal $P$. vitticeps and their eggshells and 12 eggshells of $U$. geyri were sampled to detect the presence of D. agamarum. For this purpose, the eggshells were rinsed in $2 \mathrm{ml}$ of sterile phosphate buffered saline (PBS), followed by culturing swabs, drenched into this suspension, on CNA during 24 to 48 hours at $37{ }^{\circ} \mathrm{C}$ and $5 \% \mathrm{CO}_{2}$.

All colonies, morphologically similar to D. agamarum were further analysed as described above.

\subsection{Experimental inoculation of Pogona vitticeps with Devriesea agamarum}

D. agamarum strain IMP 2, isolated from the liver of a dead Agama impalearis, was incubated for 24 hours at $37{ }^{\circ} \mathrm{C}$ and $5 \% \mathrm{CO}_{2}$. Ten colonies were harvested and transferred in $5 \mathrm{ml}$ of brain heart infusion (BHI) broth. Again, this suspension was incubated for 24 hours at $37^{\circ} \mathrm{C}$ and $5 \% \mathrm{CO}_{2}$. The inoculum was diluted with PBS to an optic density of 1.015 , which equalled $10^{8} \mathrm{cfu} / \mathrm{ml}$.

Twelve captive bred Pogona vitticeps were used in this study, which was approved by the ethical committee of the Faculty of Veterinary Medicine, Ghent University. All animals were found to be clinically healthy and free of intestinal 
116 parasites. The lizards were divided in two groups: one group was inoculated 117 with D. agamarum and the other served as a negative control group. All 118 experimental animals were 6 weeks old, weighed 4 to 10 gram and were 119 randomly assigned to one of both groups. The lizards were housed in a room 120 where temperature reached an average of $28-30{ }^{\circ} \mathrm{C}$ during 12 hours a day. Self 121 ballasted bulbs (Powersun ${ }^{\circledR}$, Zoomed) were installed in the enclosures to 122 provide the necessary ultra-violet light and to create a local hot spot.

123 After local disinfection with ethanol, the following lesions were inflicted in 3 124 places at the right side in each animal using a 26 gauge needle (Terume Europe 125 N.V., Leuven, Belgium): 1) 3 scratches in the outside border of the upper lip 2) 126 scratch at the medial side of the right knee and 3) 3 parallel dermal 127 perforations in the dorsolateral skin over a distance of $0.5 \mathrm{~cm}$. The bacterial 128 suspension was applied onto the lesions of the lip and the knee, using a swab 129 drenched into the inoculum. A 27 gauge needle (Terume Europe N.V., Leuven, 130 Belgium) was used to infiltrate a total of $200 \mu \mathrm{l}$ of the bacterial suspension, 131 containing $2 \times 10^{7} \mathrm{cfu}$, into the lesions of the dorsolateral skin. At the left side of 132 each lizard intact skin was inoculated with the bacterial suspension at the 3 133 corresponding sites. The lizards of the negative control group were inflicted 134 similar lesions but sterile PBS was applied instead of the inoculum.

135 Seventeen and 24 days post inoculation (P.I.), swabs were collected from all 136 inoculated sites and examined for the presence of D. agamarum as described 137 above. In all of the challenged and negative control animals, full thickness skin 138 biopsies were taken at 17 days P.I. from the inoculated areas of intact and 

abraded dorsolateral skin. Tissues were collected in formalin, embedded in

140 paraffin followed by haematoxylin eosin and Gram staining after sectioning.

\section{RESULTS}

\subsection{Devriesea agamarum is associated with dermatitis, cheilitis and} septicaemia in captive lizards

During a 3 year period 16 cases of D. agamarum related dermatitis and/or septicaemia in lizards were demonstrated (Table 1). D. agamarum was isolated from proliferative, hyperkeratotic dermal lesions in 1 Agama impalearis, 2 Crotaphytus collaris and 2 Uromastyx acanthinura. Other isolates were recovered from cheilitis lesions in 1 C. collaris, 1 Pogona vitticeps, $5 U$. acanthinura (Fig. 1) and 2 U. geyri. One strain was isolated from the liver of a dead A. impalearis (IMP 2) and 1 strain from the bone marrow of a dead $U$. geyri.

\subsection{Devriesea agamarum is part of the oral microbiota in healthy bearded} dragons (Pogona vitticeps)

159 D. agamarum was isolated from the border of the oral cavity in 8 clinically healthy $P$. vitticeps reared separately from other lizard species. Moreover, the 
bacterium was demonstrated in the oral cavity of 2 healthy bearded dragons cohabiting for several years with an $U$. acanthinura showing severe dermal lesions from which D. agamarum was isolated. D. agamarum could not be detected in any of the 21 clinically healthy lizards of the genus Uromastyx, 28 neonatal bearded dragons or 40 eggshells.

167

3.3. Devriesea agamarum causes dermal lesions in bearded dragons (Pogona vitticeps)

170

None of the negative control animals developed dermal pathology. The applied lesions healed in a few days time.

At 5 days post infection (P.I.) all 6 inoculated lizards had developed a macroscopic dermatitis in the area of the applied dorsolateral skin lesions. In 2 lizards the development of multiple plaques was noted and in 4 out the 6 inoculated lizards nodular lesions were observed. These nodules had an average, maximal diameter of $3 \mathrm{~mm}$ and height of $2.5 \mathrm{~mm}$ at the end of the trial. All these dorsolateral lesions showed a discoloured, irregular and scabby superficial aspect at the end of the observation period. scratches made in the right upper lip. This was accompanied by a discrete but diffuse swelling of the right edge of the oral cavity during the last days of the trial. In one inoculated animal a scabby lesion was noted at the left edge of the mouth where the inoculum was applied onto intact skin. 
At the medial surface of the knee, a distinctive crust was observed at 7 days P.I. in 5 inoculated lizards. From all of the lesions at the right side dorsolateral region D. agamarum could be isolated during the last week of the trial. From the inoculated sites at the right side lips and knees, D. agamarum could be isolated in 3 and 4 lizards, respectively. The bacterium could not be isolated from inoculation sites without applied lesions, not even from the scabby lesion at the left edge of the mouth that was observed in one inoculated animal. In all 6 inoculated lizards but in none of the negative control animals, pathological changes were observed in the skin biopsies (Fig. 2 a, b). These was apparent in 4 out of 6 samples. In all of the sections extensive colonisation of the superficial corneal layers by rod-shaped, Gram positive bacteria was observed. Hyperaemia, moderate edema and the perivascular influx of heterophils were present in the dermis. 


\section{DISCUSSION}

209

210 D. agamarum was recently designated to a novel genus and species on the basis

211 of morphological, chemotaxonomic and phylogenetic differences from other

212 coryneform bacteria. For this Gram positive, rod shaped and non sporulating

213 bacterium, Brachybacterium faecium (95\%) and Dermabacter hominis (95\%)

214 were determined as nearest phylogenetic neighbours based on 16S rRNA gene

215 sequence analysis (Martel et al., in press). The occurrence of dermal disease in

216 reptiles has also been associated with other members of the phylum

217 Actinobacterium, such as Dermatophilus and Mycobacterium species (Chineme

218 and Addo, 1980; Greer et al., 2003; Wellehan et al., 2004).

219 D. agamarum was isolated from several clinical cases of naturally infected

220 lizards indicating this bacterium to be involved in chronic dermatitis that can

221 result in septicaemia. Especially desert dwelling species seem to be more

222 susceptible to the development of $D$. agamarum associated dermatitis.

223 Particularly in Uromastyx lizards, the bacterium was isolated from all cheilitis

224 and dermatitis cases included in this study. In fact, cheilitis in Uromastyx

225 lizards, often combined with dermatitis, is one of the most frequently occurring

226 diseases in these lizards in captivity.

227 D. agamarum was isolated from the oral cavity in 8 clinically healthy $P$.

228 vitticeps reared isolated from other lizard species as well as in 2 healthy $P$.

229 vitticeps cohabiting with a D. agamarum infected Uromastyx. Therefore D.

230 agamarum can be considered a common constituent of the oral microbiota of 
captive $P$. vitticeps. Despite the relatively high occurrence in this species, isolation of $D$. agamarum could only be achieved at one occasion from a $P$. vitticeps with cheilitis. On the other hand, the bacterium was not isolated from any of the clinically healthy Uromastyx lizards. Combined with the high occurrence of D. agamarum in diseased Uromastyx, this finding suggests a species dependent sensitivity to D. agamarum associated disease. Moreover, bearded dragons might represent a reservoir of the bacterium for squamate species highly sensitive to D. agamarum associated disease.

Strain IMP 2 of D. agamarum isolated from the liver of a dead A. impalearis induced dermatitis in all of the 6 inoculated animals during a 24 day observation period and the agent was re-isolated from these lesions. Hence Koch's postulates were fulfilled (Evans, 1976; 1977).

Despite using a strain isolated from the liver of an animal that died due to septicaemia, in none of the challenged lizards signs related to systemic spread of D. agamarum were seen. Variation in length of the observation period or the inoculated lizard species could influence the outcome of infection with $D$. agamarum.

D. agamarum associated dermatitis could only be provoked after inoculation of skin lesions. Dermatitis could not be induced by inoculating intact skin. Therefore, skin lesions appear to be necessary to develop D. agamarum related dermatitis. 
252 In conclusion, this study demonstrates that D. agamarum is part of the oral 253 microbiota of $P$. vitticeps and is able to cause cheilitis, dermatitis and 254 septicaemia in lizards using skin lesions as a portal of entry.

255

256

257

258

259

260

261

262

263

264

265

266

267

268

269

270

271

272

273

274 
1. Chineme, C.N., and Addo, P.D., 1980. Pathologic changes in lizards (Agama agama) experimentally infected with Dermatophilus congolensis. J. Wildl. Dis. 16, 407-412.

2. Evans, A.S., 1976. Causation and disease: the Henle-Koch postulates revisited. Yale J. Biol. Med. 49, 175-195.

3. Evans, A.S., 1977. Limitations of Koch's postulates. Lancet 2, 1277-1278.

4. Frank, W., 1976. Mycotic infections in amphibians and reptiles. In: Page, L.A. (ed.), Wildlife diseases, Plenum Press, New York. pp. 73-88.

5. Greer, L.L., Strandberg, J.D., Whitaker, B.R., 2003. Mycobacterium chelonae osteoarthritis in a Kemp's ridley sea turtle (Lepidochelys kempii). J. Wildl. Dis. 39, 736-741.

6. Harkewicz, K.A., 2000. Dermatology of Reptiles: A clinical approach to diagnosis and treatment. Vet. Clin. North. Am. Exotic Anim. Pract. 4, 441461.

7. Herbst, L.H., Jacobson, E.R., Klein, P.A., Balazs, G.H., Moretti, R., Brown, T., Sundberg, J.P., 1999. Comparative Pathology and pathogenesis of spontaneous and experimentally induced fibropapillomas of green turtles (Chelonia mydas). Vet. Pathol. 36, 551-564.

8. Jacobson, E.R., 1992. Reptile dermatology. In: Kirk, R.W., Bonagura, J.D. (eds.), Kirk’s Current Veterinary Therapy XI, Small animal practice, W.B. Saunders, Philadelphia, pp. 1204-1210. 
9. Jacobson, E.R., Cheatwood, J.L., Maxwell, L.K., 2000. Mycotic diseases of reptiles. Seminars in avian and exotic pet medicine. 9, 94-101.

10. Koplos, P., Garner, M., Besser, T., Nordhausen, R., Monaco, R., 2000. Cheilitis in lizards of the genus Uromastyx associated with a filamentous Gram positive bacterium. Proceedings of the Association of Reptilian and Amphibian Veterinarians, pp. 73-75.

11. Martel, A., Vandamme, P., Hellebuyck, T., Haesebrouck, F., Pasmans, 305 F. Devriesea agamarum gen. nov., sp. nov., A novel actinobacterium isolated from dermatitis in agamid lizards. Int. J. Syst. Evol. Microbiol., in press.

12. Paré, J.A., Coyle, K.A., Sigler, L., Maas, A.K., Mitchell, R.L., 2006. Pathogenicity of the Chrysosporium anamorph of Nannizziopsis vriesii for veiled chameleons (Chameleo calyptratus). Med. Mycol. 44, 25-31.

\section{Pasmans, F., Martel, A., van Heerden, M., Devriese, L., Decostere, A.,} Haesebrouck, F., 2004. Dermatitis and septicaemia in a captive population of Agama impalearis caused by unknown Actinobacteria. Proceedings of the $7^{\text {th }}$ International Symposium of Pathology and Medicine of Reptiles and Amphibians, Berlin, Germany.

14. Pasmans, F., Blahak, S., Martel, A., Pantchev, N., 2007. Introducing reptiles into a captive collection: The role of the veterinarian. Veterinary Journal, DOI 10.1016/j.tvj1.2006.12.009.

15. Raynaud, A., Adrian, M., 1976. Lesions cutanee a structure pilomateuse associees a des virus chez lezard vert (Lacerta viridis Laur). Comptes Ren- 

dus de l'Académie de Sciences (Paris). 283(Series D), 845. 
Figure 1. Spiny tailed lizard (Uromastyx acanthinura) with Devriesea agamarum associated cheilitis presented as chronic hyperkeratosis.

Figure 2. HE stained sections of dorsolateral skin collected in bearded dragons (Pogona vitticeps), 17 days after inoculating dermal perforations either with PBS (a) or Devriesea agamarum strain IMP 2 (b).

(a) A relatively thin Stratum germinativum

and Stratum corneum, melanocytes and normal dermis with loose connective tissue are apparent. Scale bar $=50 \mu \mathrm{m}$.

(b) Note the epidermal hyperplasia with orthokeratosis, serocellular crust formation and hyperaemia. Scale bar $=50 \mu \mathrm{m}$. sg, Stratum germinativum; sc, Stratum corneum; mc, melanocyt; d, dermis; hp, epidermal hyperplasia; ok, orthokeratosis; s, serocellular 
Table 1. Bacteria and/or fungi isolated as pure and/or abundant cultures from 28 clinical dermatitis cases in lizards.

\begin{tabular}{|c|c|c|c|}
\hline $\begin{array}{l}\text { Wild caught }(W C) \\
\text { or captive bred } \\
(\mathrm{CB})\end{array}$ & Lizard species & Lesions & $\begin{array}{l}\text { Bacteriological } \\
\text { and/or mycological } \\
\text { agent identified }\end{array}$ \\
\hline $\mathrm{CB}$ & Pogona vitticeps & Dermatitis & No \\
\hline $\mathrm{CB}$ & Pogona vitticeps & Cheilitis & Devriesea agamarum \\
\hline $\mathrm{WC}$ & Agama impalearis & Dermatitis & Devriesea agamarum \\
\hline $\mathrm{WC}$ & Agama impalearis & Dermatitis/Septicaemia & Devriesea agamarum \\
\hline $\mathrm{WC}$ & $\begin{array}{l}\text { Physignathus } \\
\text { concincinus }\end{array}$ & Dermatitis & $\begin{array}{l}\text { Dermatophilus } \\
\text { congolensis }\end{array}$ \\
\hline $\mathrm{CB}$ & $\begin{array}{l}\text { Physignathus } \\
\text { concincinus }\end{array}$ & Dermatitis & Staphylococcus aureus \\
\hline $\mathrm{CB}$ & $\begin{array}{l}\text { Physignathus } \\
\text { concincinus }\end{array}$ & Dermatitis & Staphylococcus aureus \\
\hline $\mathrm{CB}$ & $\begin{array}{l}\text { Physignathus } \\
\text { concincinus }\end{array}$ & Dermatitis & Staphylococcus aureus \\
\hline $\mathrm{WC}$ & $\begin{array}{l}\text { Uromastyx } \\
\text { acanthinura }\end{array}$ & Dermatitis & Devriesea agamarum \\
\hline $\mathrm{WC}$ & $\begin{array}{l}\text { Uromastyx } \\
\text { acanthinura }\end{array}$ & Dermatitis & Devriesea agamarum \\
\hline $\mathrm{WC}$ & $\begin{array}{l}\text { Uromastyx } \\
\text { acanthinura }\end{array}$ & Cheilitis & Devriesea agamarum \\
\hline $\mathrm{WC}$ & $\begin{array}{l}\text { Uromastyx } \\
\text { acanthinura }\end{array}$ & Cheilitis & Devriesea agamarum \\
\hline $\mathrm{WC}$ & $\begin{array}{l}\text { Uromastyx } \\
\text { acanthinura }\end{array}$ & Cheilitis & Devriesea agamarum \\
\hline $\mathrm{WC}$ & $\begin{array}{l}\text { Uromastyx } \\
\text { acanthinura }\end{array}$ & Cheilitis & Devriesea agamarum \\
\hline $\mathrm{WC}$ & $\begin{array}{l}\text { Uromastyx } \\
\text { acanthinura }\end{array}$ & Cheilitis & Devriesea agamarum \\
\hline $\mathrm{WC}$ & Uromastyx geyri & Dermatitis/Septicaemia & Devriesea agamarum \\
\hline $\mathrm{WC}$ & Uromastyx geyri & Cheilitis & Devriesea agamarum \\
\hline $\mathrm{WC}$ & Uromastyx geyri & Cheilitis & Devriesea agamarum \\
\hline $\mathrm{CB}$ & Crotaphytus collaris & Dermatitis & Devriesea agamarum \\
\hline $\mathrm{CB}$ & Crotaphytus collaris & Dermatitis & Devriesea agamarum \\
\hline $\mathrm{CB}$ & Crotaphytus collaris & Cheilitis & Devriesea agamarum \\
\hline $\mathrm{CB}$ & Iguana iguana & Dermatitis & Nannizziopsis vriesii \\
\hline $\mathrm{CB}$ & Iguana iguana & Dermatitis & No \\
\hline $\mathrm{CB}$ & Iguana iguana & Dermatitis & No \\
\hline $\mathrm{CB}$ & Iguana iguana & Dermatitis & No \\
\hline $\mathrm{CB}$ & Iguana iguana & Dermatitis & Staphylococcus aureus \\
\hline $\mathrm{CB}$ & Iguana iguana & Dermatitis & Staphylococcus aureus \\
\hline $\mathrm{WC}$ & Cyclura nubila & Dermatitis & No \\
\hline
\end{tabular}




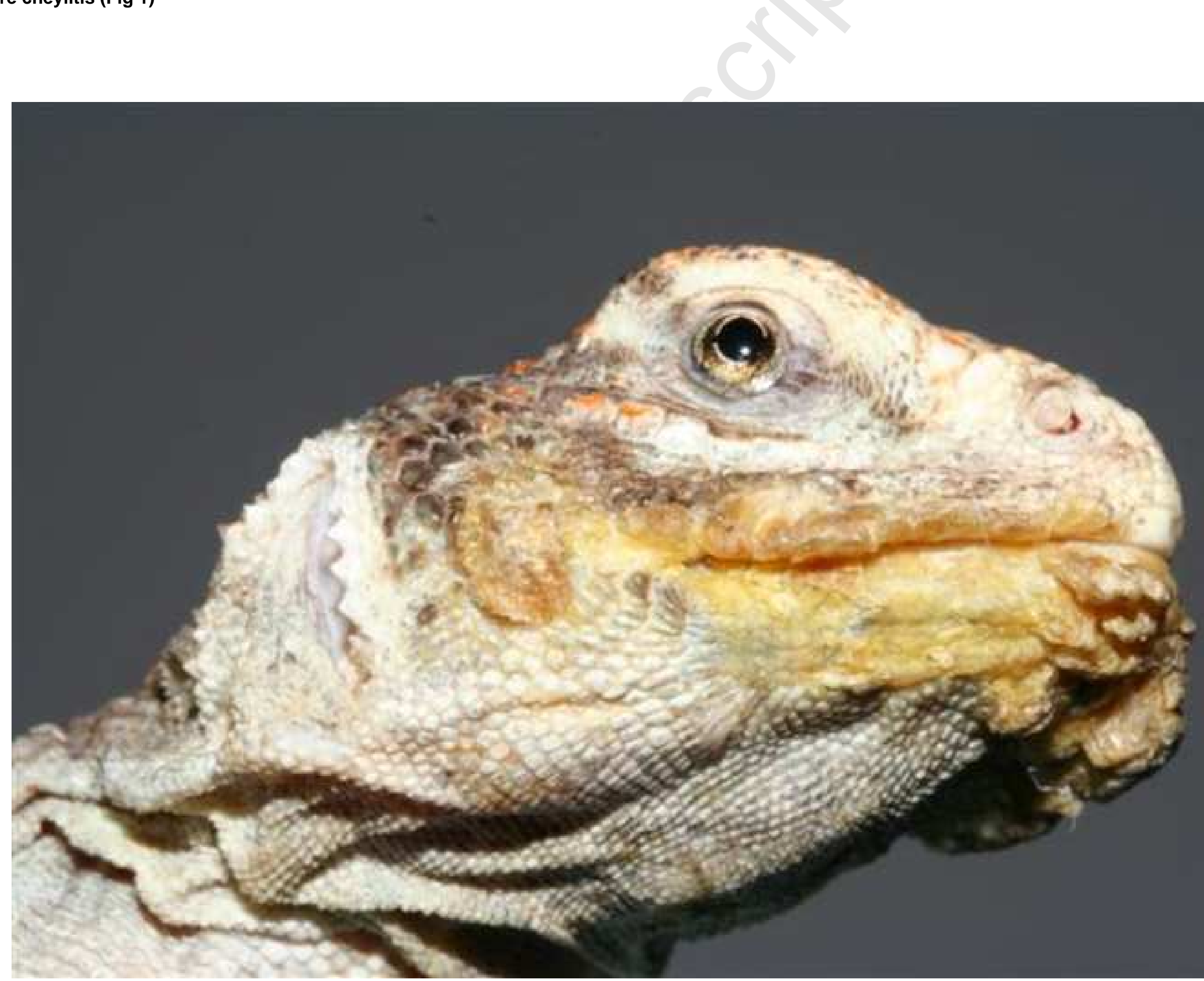

Page 18 of 20 
Histological image normal skin (Fig 2a)

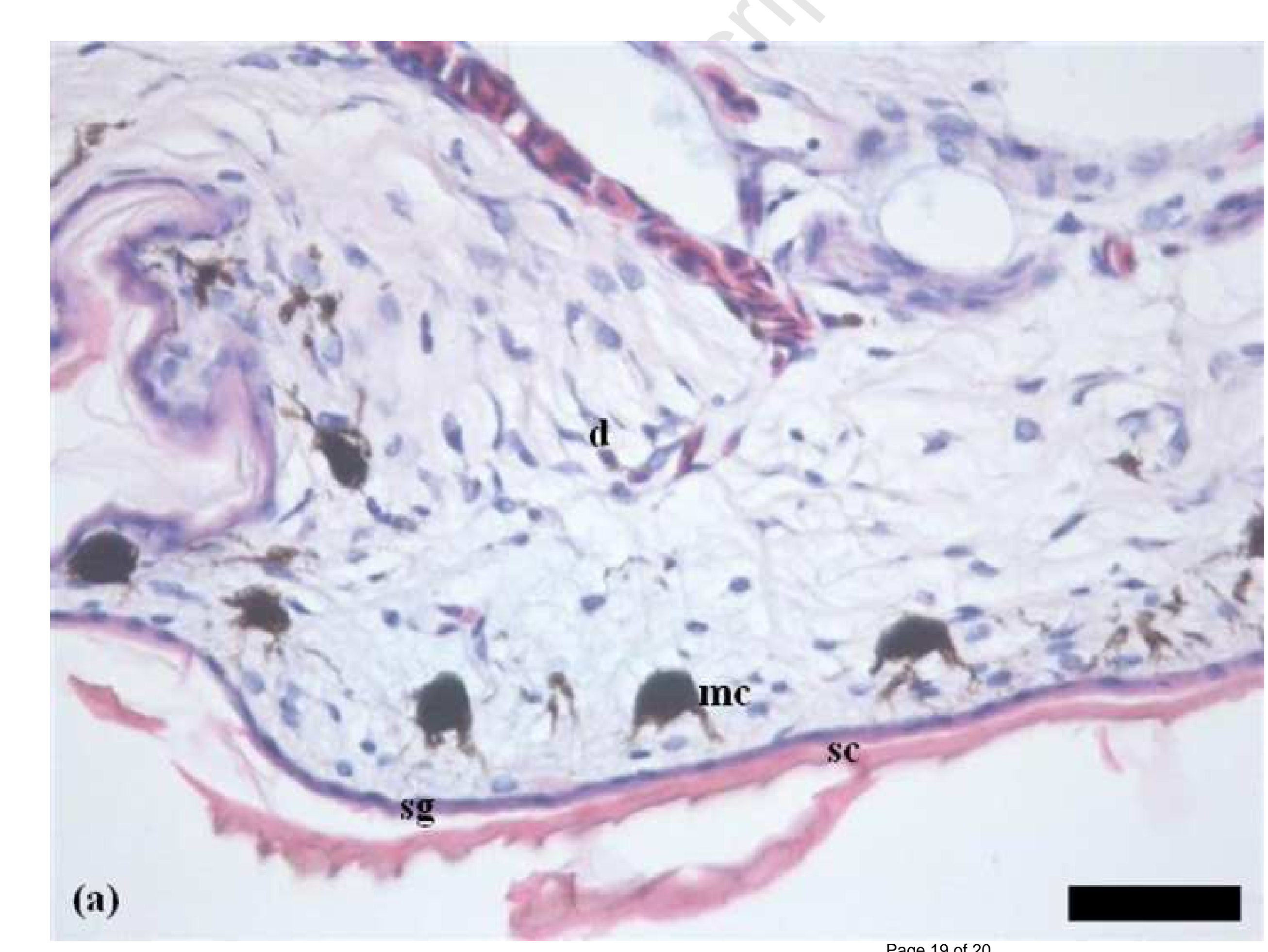

Page 19 of 20

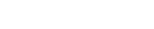




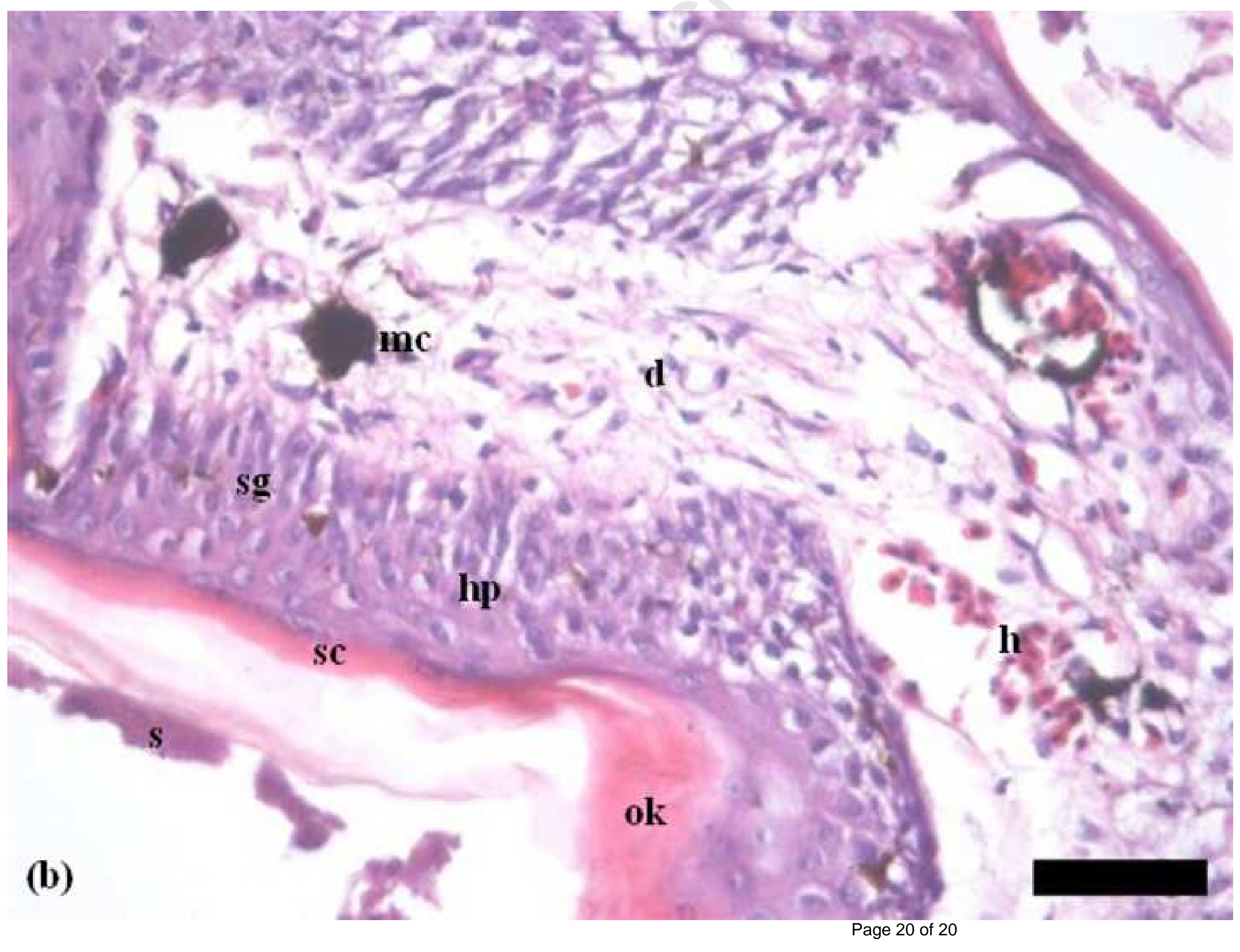

